\section{Historietas herméticas,} aproximación a la tira dibujada desde la obra de E. A. Vigo.

Julia Cisneros

Recebido em: 10 de abril de 2017 Aceito em: 28 de agosto de 2017
Julia Cisneros

Licenciada en Letras Modernas, Universidad Nacional de Córdoba, estudiante de la Maestría en Estética y Teoría de las Artes, Universidad Nacional de La Plata. Investigadora en el Centro de Arte Experimental Vigo, adscripta en el equipo de investigación Heterodoxias y Sincretismos en el Sistema Literario Argentino sislos XIX y XX. Directora: Cecilia Corona Martínez, UNC.

Contato: julia_cisneros@hotmail.com

Aceito en: 28 de agosto de 2017 
Palabras clave: Historieta Resumen: El Centro de Arte Experimental Edgardo Antonio Vigo hermética; Edgardo Antonio (CAEV) ubicado en la ciudad de La Plata, alberga la obra del artista Viso; Hexásono 71'; experimental Edgardo Antonio Vigo (1928-1997) desde 1997. reescritura.

KEYWORDS: Hermetic comic ${ }_{i}$ La multiplicidad de disciplinas con las que trabajó este artista, incluye de manera particular el género de la historieta. Este trabajo se enmarca en una investigación más amplia referida al conjunto de reescrituras de E. A. Viso; subdivididas en traducciones, selección de artículos y ensayos personales. Trabajaremos en este caso, con cinco de estas reescrituras referidas a la temática de la historieta, senerando lazos con su obra plástica plasmada en la revista ensamblada Hexágono 71' (1971-1975). Dividimos el trabajo en dos momentos, el primero de ellos refiere a la temática de las reescrituras, el segundo analiza las historietas de Vigo en la publicación de Hexágono 71'.

Edgardo Antonio Vigo; Abstract: Centro de Arte Experimental Edgardo Antonio Viso Hexásono 71'; rewriting. (CAEV), located in the city of La Plata, has housed the work of the experimental artist Edgardo Antonio Vigo (1928-1997) since 1997. The multiplicity of disciplines with this highly prolific artist has worked includes the genre of comics. This work is part of a broader research referring to $E$. A. Vigo group of rewritings, subdivided into translations, a selection of articles and personal essays. In this case we will work with five of these rewritings referring to the subject of the comics, generating links with his plastic work embodied in the "assembled magazine" Hexágono 71' (1971-1975). We divide the work in two moments: the first refers to the subject of rewriting, the second analyzes Vigo's comics in the publication of Hexágono $71^{\prime}$. 


\section{ESCRITURAS SOBRE LA TIRA DIBUJADA}

El Centro de Arte Experimental Vigo cuenta con un amplio número de publicaciones nacionales y extranjeras referidas a la historieta en su acervo documental. Estos textos nos orientan sobre la preocupación de Edgardo Antonio Vigo por dicho género, pero, además, permiten reflexionar sobre los discursos que circulaban el auge de la historieta en la Argentina y aportan claves de lectura sobre las producciones en la que Vigo opera como editor y productor; nos referimos específicamente a la publicación Hexágono 71' (1971-1975).

Dos críticos contemporáneos al corpus seleccionado, cuyos pensamientos encontramos en la biblioteca personal de Vigo, plasman versiones sobre este género que sirven para abordar la propuesta estética del artista platense.

La mirada de Umberto Eco, en Apocalípticos e Integrados (1968), postula que las críticas apocalípticas surgen de la lectura de textos sobre la cultura de masas mientras que la imagen de quienes se integran surge de las lecturas de la cultura de masas (Eco, 1968, 13). Vigo, como mencionamos, es un gran lector del comic, en su hacer estético utiliza los recursos provistos por la cultura de masas como una herramienta para ampliar las posibilidades de las artes visuales articulando sus elementos con la poesía visual, proyectos de arte correo y edición. En este sentido coincidiría con Eco al considerar que la eficacia de una intervención en la cultura de masas reside en un conocimiento del material sobre el cual se trabaja (Eco, 1968, 62). Tomando elementos conocidos para subvertirlos, Vigo busca fisurar los modos establecidos de decodificar estas producciones. Se vinculó también 
con las comunicaciones de masa desde su producción escrita, puesto que publica para el diario El Argentino una sección denominada Artes Plásticas desde 1961.

Eco indica algunas propuestas de investigación sobre el comic que creemos pertinentes en relación a las novedades formales del comic que interesan para analizar la estética de Vigo:

La sucesión cinematográfica de los strips. Ascendencia histórica. Diferencias. Influencia del cine. Procesos de aprehesión implicados. Posibilidades narrativas conexas. Unión palabra-acción realizada mediante artificios gráficos. Nuevo ritmo y nuevo tiempo narrativo que de ahí derivan. Nuevos estilemas para la representación del movimiento (los dibujantes de comics no copian de modelos inmóviles, sino de fotogramas que fijan un momento del movimiento). Innovaciones en la técnica de la onomatopeya. Influencias de las experiencias pictóricas precedentes. Nacimiento de un nuevo repertorio iconográfico y de standardizaciones que funcionan ya como topoi para la koiné de los fruidores (destinados a convertirse en elementos de lenguaje adquirido para las nuevas generaciones). Visualización de la metáfora verbal. Estabilización de tipos caracterológicos, sus límites, sus posibilidades pedagógicas, su función mitopoética. (Eco, 1968, 72)

En el capítulo dedicado a la lectura de "Steve Canyon" el autor analiza "El lenguaje del comic" especificando los componentes de una iconografía que, si bien utiliza estereotipos, el género del comic se los apropia, aportando elementos gráficos - el espiral de humo, cabeza que da vueltas, lámpara encendida como idea, etc.- ellos nos permiten hablar, en términos de Eco, de una semántica del comic donde encontramos el signo convencional 
de la burbuja, y la colección de recursos onomatopéyicos trasladados a la escritura. En relación a la gramática del encuadre, contempla la perspectiva, ubicación de los personajes, el enriquecimiento o literalidad de la imagen en relación al texto.

La naturaleza de la trama, los estereotipos, así como los valores que la historieta promueve pertenecen a una lectura crítica del comic por la cual: El comic esta ideológicamente determinado por su naturaleza de lenguaje elemental fundado en un código muy sencillo, fundamentalmente rígido, obligado a narrar por medio de personajes estándar, forzado en gran parte a servirse de formas introducidas ya por otras artes y adquiridas por la sensibilidad del gran público tras un sensible lapso de tiempo, aisladas del contexto original y reducidas a puros artificios convencionales (Eco, 1968,181)

En esta reflexión las determinaciones ideológicas se imponen tanto en el lector como en el autor. En el primero por las características en la estructura sintáctica del género, en el segundo por los condicionamientos del mercado.

Según el autor, concibiendo una historieta que, haciendo uso de estos elementos, manifieste una visión distinta "el problema se fragmenta en una serie de casos concretos y no abarca el género como tal" (Eco, 1968, 182). Si los modos de circulación determinan el universo de lo representable de la historieta, debemos considerar que, las maneras heterodoxas de abordar el género por parte de Vigo, así como también de artistas como Alvaro de Sá, se dan en el marco de publicaciones que tienen un alcance reducido 
y permanecen por fuera de los circuitos hegemónicos de circulación. Esta condición no quita relevancia al nivel de experimentación plasmada en estas obras y permite otro tipo de flexibilidad respecto de aquellos condicionamientos que menciona Eco.

Aludir, por último, y en relación a los modos de circulación, Fragmentos de la Microedición, título de la muestra de fanzinotecas realizada en el mes de Agosto de 2017 en el Centro Cultural Ricardo Rojas, curada por Alejandro Bidegaray y Alejandro Schmied; en ella, las categorías de ordenamiento del material se dividían en: Universos Representados, Tres décadas de Historietas argentinas, Diálogos contraculturales, El murmullo creciente de las revistas subte, Fragmentos de comunicación urgente, Punk y derivados. Esta exposición da cuenta de la amplia gama de temáticas silenciadas que tuvieron su voz en las revistas y micro-ediciones argentinas desde la década del 60 hasta los años 2000. Donde la plataforma autogestiva en relación con la historieta "va a seguir desarrollándose y hacia fin de siglo va a constituir, no un emergente, sino el sostén vital de la producción local de historietas" (texto de muestra, sin catálogo, 2017)

Dijimos que otro crítico que figura en la Biblioteca de Vigo es Oscar Masotta. Él organiza en 1968 la Bienal Mundial de la Historieta conjuntamente con la Escuela Panamericana de Arte en el Instituto Di Tella. El mismo año dirige la revista Literatura Dibujada. Serie de Documentación de la Historieta Mundial ( ${ }^{\circ} 1$ : noviembre de $1968-\mathrm{n}^{\circ} 3$ : enero de 1969), y en 1970 publica La historieta en el mundo moderno, donde afirma: "En la historieta todo significa, o bien, todo es social y moral" (Masotta, 9, 
1970). Analiza los elementos y las mutaciones de las historietas en Estados Unidos, Europa y Argentina respectivamente. Masotta habla del "comic" para referir a la historieta estadounidense mientras que utiliza el término "historieta" cuando refiere al género en Europa y Argentina.

Resulta pertinente resaltar que en el Fondo Documental del CAEV, encontramos la revista mencionada anteriormente Literatura Dibujada. Serie de Documentación de la Historieta Mundial ( ${ }^{\circ}$ 1: noviembre de 1968 $-\mathrm{n}^{\circ}$ 3: enero de 1969). Esta revista propone al lector:

(...)reeditaremos las mejores historietas del pasado e invitaremos al lector a conocer las mejores historietas del presente, sorpresivamente dirigidas al público adulto (...) El proyecto de L. D - una actitud de reflexión militante sobre la historieta- puede parecer complejo, más aun contradictorio (...) porque tal vez en ninguna época más que en la nuestra, ni de modo más agudo, las cuestiones del gusto se han hecho más chocantes en relación a aquellas referidas a la política, a la ideología, a la moral. (L. D. $n^{\circ} 1$, pag. 3.)

Señala Maria Virginia Castro sobre el contexto de esta publicación:

La aparición de Literatura Dibujada. Serie de Documentación de la Historieta Mundial constituye un primer gran intento vernáculo de promocionar a la Argentina no sólo como un país productor de narrativas dibujadas, sino de una producción teórica de vanguardia sobre este producto específico de la cultura de masas. Las razones de su fracaso (si fue tal) estriban seguramente en que fue un proyecto que quedó trunco demasiado pronto, sin lograr por ello ajustar (su director) las variadas matrices teóricas con las que abordó su objeto, ni resolver las tensiones entre su público ideal y su público posible. No obstante, los tres números de LD, hoy prácticamente inhallables como totalidad en las hemerotecas de consulta pública, no han perdido 
-creemos- su "poder encantatorio.". (Castro, "Literatura Dibujada: El desafío de comprometer la historieta", sin fecha).

En el transcurso de este artículo presentamos una posible hipótesis sobre la incidencia de esta publicación en la obra de Vigo.

\section{Reescrituras de Edgardo Antonio Vigo.}

Dentro de la biblioteca personal de Vigo, donde ubicamos la serie de revistas de y sobre la historieta anteriormente citadas, encontramos la sub serie denominada "Reescrituras". Corresponden a traducciones completas de libros del francés, realizadas por su esposa, Elena Comas, selección de artículos y ensayos personales respectivamente. Todos estos se configuran como nuevos originales. Son ejemplares únicos mecanografiados y re diagramados por Vigo. Las tres temáticas que hemos relevado refieren fundamentalmente a: vanguardia histórica, poesía visual e historietas. Las dos primeras quedan fuera de la presente investigación pero forman parte del trabajo en curso.

Las reescrituras que refieren al comic y la historieta en su archivo corresponden a:

"La burbuja en la tira dibujada",

"La tira dibujada",

"Las obras maestras de la tira dibujada",

"Banda Ilustrada y Figuración narrativa",

Por último, una selección de diecinueve artículos de la revista Panorama, 
Diario El Día, entre otros. Este ejemplar cuenta con imágenes, recortes e ilustraciones del propio Vigo.

En la mayoría de las reescrituras no figuran las fechas en las que fueron realizadas, según el relevamiento realizado por Berenice Gustavino, serían de fines de la década del 60' y comienzos de los 70'.

A continuación desarrollaremos brevemente las temáticas de cada una de ellas para, posteriormente, analizar los modos en que Vigo vuelve a significar el género, cuestiona y deglute, antropofágicamente, estos materiales teóricos en la revista Hexágono 71'.

"La burbuja en la tira dibujada", de Robert Benayoun, es un ensayo publicado inicialmente en el año 1963 en la revista Bréche-Action surréaliste $\mathrm{n}^{\circ} 4$, bajo el título "Le ballon dans les bandes dessinées". En la reescritura de Vigo figura la edición posterior, fechada en 1968 con la traducción de Elena Comas, no encontrándose el libro original al que remite en su biblioteca.

Según el autor, la burbuja en la tira dibujada no es solo la manifestación de un sentir, ni es solamente una manera de animar a los personajes; es una de las formas de visibilizar el pensamiento. En el globo de la tira dibujada, tanto la palabra escrita como la imagen devienen en expresión y materialización de convenciones icónicas para la comprensión de ese discurso, convenciones que dan cuenta de los grados de acuerdo y las tensiones entre los símbolos que representa. Las convenciones con las que trabaja apelan a unos sentidos culturalmente construidos (lámpara=idea). 
Por lo anterior la burbuja, el globo, son propuestas para un determinado sistema de notación del pensamiento basado en lo icónico.

El poeta brasileño Álvaro de Sá presenta para la Expo Internacional de Novisima Poesía 69, organizada por Vigo en el Instituto Di Tella (1969), dos obras: "Cuatro Poema Proceso" del libro 12x9.

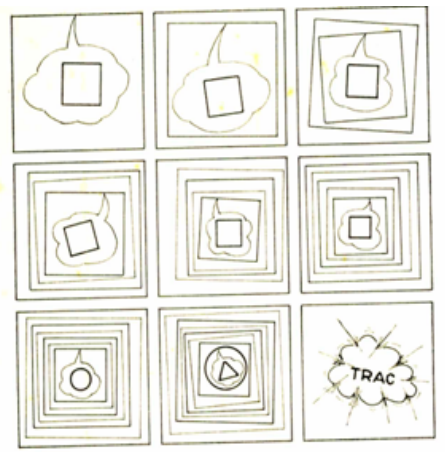

Fis. 1: Álvaro de Sá, Cuatro poema proceso. Fragmento. Archivo CAEV.

En la imagen seleccionada la burbuja aparece vacía de palabra. Eliminar del interior de la burbuja su contenido convencional sugiere una supresión de la información, no importa lo que se diga sino cómo se materialice ese signo puesto que la palabra dicha viene desde fuera de la vińeta. No hay sujeto que enuncia o bien todos los sujetos son enunciadores; esa palabra en nube paulatinamente va encerrándose hasta que en las dos últimas vińetas cambia su composición geométrica y, finalmente, explota. 
No es menor el hecho de que Álvaro de Sá presente estas obras en una exposición de novísima poesía visual. La operación estética en esta muestra se orientó a promover un tipo de producción donde la hibridez y la experimentación exceden los límites que proponen las categorías de la poesía tradicional. Se trabaja con las convenciones para alterarlas, revulsionarlas en términos de Vigo. Retomamos las palabras de otro brasilero participante de la Novisima, Moacy Cirne: "Trabajar sobre el lenguaje implica, en el nivel organizativo de su formulación, hacer experiencias con los signos que la estructuran reconociendo procesos continuos en busca de información nueva" (Cirne, 16,1975 trad. Cisneros)

La segunda reescritura del ańo 1969 corresponde a "La tira dibujada, Historia de las Historietas en Imágenes de la Pre-historia hasta nuestros días", de Gerard Blanchard, no posee ilustraciones en su interior. En el archivo se encuentra el texto de referencia. Transcribimos del primer párrafo de la traducción de Elena Comas:

Hay numerosas definiciones posibles de la tira dibujada. La más común restringe el término a designar solamente las historietas en imágenes de estilo americano que vieron la luz a fines del último siglo en los periódicos de allende el Atlántico y se perfeccionaron bajo la influencia del cine y mucho más gracias a algunos dibujantes de muy alta calidad. Nos daremos cuenta al hojear este libro que queremos adoptar un punto de vista más amplio, una definición más literaria que nos permita comprender tanto los bajo relieve de la columna de trajano como la tapicería Bayeux, los frescos de Assis, como algunas imágenes de Epinal, los álbumes de Töpffer como los de Tarzan y Asterix. 
El desarrollo histórico que propone ubica la historieta como un hibrido entre la literatura y las artes visuales, expone vínculos con movimientos como el futurismo y el pop-art.

El tercer libro corresponde a "Las obras maestras de la tira dibujada". Con prefacio del guionista y editor Rene Goscinny. En el acervo del CAEV encontramos números de la revista "Pilote" y el libro original sobre el que se realiza la reescritura.

La reescritura ${ }^{\circ}$ 4, "Banda Dibujada y Figuración Narrativa", figura en la publicación Hexágono $71^{\prime}$ a. Se transcribe un fragmento del prefacio de Burne Hogarth, fechado en enero de 1968 bajo el mismo título:

Por algún motivo oscuro, existe, entre los círculos informados, en particular aquellos que determinan la apreciación de las artes, antiguas y aceptadas o nuevas y aceptables, una indiferencia, y hasta una ignorancia voluntaria, hacia la tira dibujada. Para algunos mandarines, cuando se discute de arte y de gusto, por solo mencionar las palabras "cartón" o "tira dibujada", desencadena una reacción de desdén, sino de desprecio.

Sugiere Hogarth que la tira dibujada encontrará su lugar en las Bellas Artes, cuando se la defina en relación con las artes tradicionales. No es menor, a la luz de estas palabras, que en el mismo número aparezcan las declaraciones del "Arte Pobre" de Celant (1968). Por otra parte, en la revista Hexágono 71' bc, Vigo traduce y realiza notas sobre el artículo de Moacy Cirne, "La importancia de la tira dibujada", aparecido en Blum! La explosión creativa de las tiras dibujadas. En las notas, el traductor vuelve sobre el artículo de Hogarth. 
Expone Cirne en el texto citado, que la historieta ha sido juzgada como una sub literatura perjudicial para la infancia. Retoma el ensayo de Benjamin ("La obra de arte...") haciendo énfasis en la idea de que técnicas de reproducción aplicadas a la obra de arte modifican la actitud de la masa frente a la obra, la historieta no queda exenta por su grado de masividad. Alude también las proposiciones de Poema/ Proceso: "Narraciones de historietas y humor, sin leyendas". Culmina el artículo señalando que: "Poco importa saber que las historietas son - o no - un arte, conforme hace notar RUY CASTRO, precisamente porque — hoy — que es realmente lo que sería arte? Lo que importa es su poder de comunicación y su capacidad de revitalizar formas expresivas”. (Hexágono 71' bc)

La última reescritura a la que aludimos corresponde a una selección de artículos, donde figura, entre otros, una semblanza del libro "Para leer al Pato Donald" extraído del diario platense El Dia con la fecha del 13 de Agosto de 1972. La crítica marxista que postulan Dofman y Mattelart (1972) sobre las tiras de Disney se orienta a desmantelar las formas de dominación plasmadas en las historietas. Además cuenta con textos extraídos de diversos suplementos como Panorama, La razón, Siete días, La Opinion, entre otros. Los artículos que componen este volumen poseen diversas fechas desde 1968 hasta 1974. El ejemplar cuenta con ilustraciones de Vigo (caso Mafalda) y diversos recortes de historietas argentinas. Se destaca esta reescritura el diseño, la construcción de un catálogo y el trabajo estético de Vigo en su edición. 


\section{Historietas Herméticas y Hexágono 71',}

Hexágono 71'es, en la denominación de Ana Bugnone, una "revista ensamblada", porque corresponde a una publicación donde prima "el montaje de trabajos de diversos artistas que un editor se encarga se aunar, similar al libro de artista y cuyas estrategias comunicativas se separan de las limitaciones del mundo editorial." (Bugnone, 7, 2014) en este tipo de publicación, los vínculos y colaboraciones entre artistas son fundamentales.

A diferencia de las revistas normativas, basadas en parámetros industriales y masivos y centradas en el deber de ceñirse y atenerse a unos cánones editoriales estandarizados por la industria -no digo sin ciertas libertades—, para llegar eficazmente a consolidarse en el mercado — sea cual sea su temática, tipo de consumidor, nivel de experimentación gráfica o distribución-, las ensambladas transgredieron esas normas y habilitaron la creación experimental, lo que permitió tanto la transformación del formato como del contenido, pero limitadas en la tirada y la difusión (Bugnone, 2014, 8 )

Entre las características específicas que señala la autora, subrayamos en primer instancia, la carencia de numeración de las revistas Vigo modifica el número por una letra, así, las primeras tres letras del alfabeto se combinan en a, ab, ac, bc, bd, be, cd, ce, cf, de, dg, df, y e conformando los trece números publicados de 1971 a 1975. Por otra parte, respecto de la materialidad, la publicación apela a un dispositivo distinto respecto de la revista tradicional, puesto que las hojas se encuentran sueltas dentro de los sobres respectivos, no poseen numeración, por lo que el espectador 
también es un hacedor que re ordena y participa en cada accionar este dispositivo.

Respecto al carácter político de esta publicación señala la autora que:

Se trata de un artefacto cuya politicidad se encuentra en el entrecruzamiento de vanguardia estética y política radicalizada, las que obtuvieron diferentes pesos a lo largo del tiempo: los modos y proporciones en que se combinaron invalidan cualquier interpretación lineal que identifique el aumento del compromiso político con el abandono de las prácticas específicamente artísticas o de la estética vanguardista (Bugnone, 2014, 4)

En la lectura de Bugnone, Hexágono 71'puede dividirse en dos etapas, una primera que comprende los primeros cuatro números $(a / b e)$ y un segundo momento, del numero ce a $e$. La división no solo se efectúa respecto del logo que emplea y la ilustración de tapa sino también al contenido de la misma, puesto que, entre otras, en la segunda etapa se da un viraje hacia autores argentinos y latinoamericanos y adquiere un perfil más comprometido políticamente.

\section{Hexágono 71'a (1971)}

En Hexágono 71' a, como mencionamos, figura "Banda Dibujada y Figuración Narrativa” de Burne Hogarth. Por vez primera encontramos el "Grupo de familia”, en la obra "Historieta". "Grupo de familia" corresponde a una tribu con cuatro personajes aparentemente prehistóricos reunidos de forma circular, como veremos, esta figura será recurrente pero no tiene un sentido único en la producción de Vigo. 


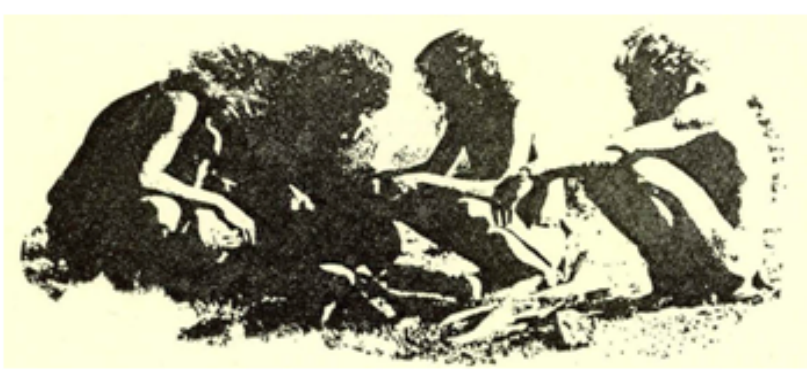

Fig. 2: Grupo de Familia. Archivo CAEV

La tira a la que aludimos consta de cinco cuadros-viñetas, dos en la hoja uno, tres en la siguiente. En la primera vemos una especie de viñeta con la letra " $\mathrm{T}$ " en la parte inferior y por sobre esta, una burbuja hecha de puntos que contiene una superposición de nubes yustapuestas. La letra "T" se repite en imagen $3^{\circ}$ y $5^{\circ}$, en la $4^{\circ}$ una letra " $S$ " compuesta geométricamente. En la segunda imagen encontramos una mixtura entre la estructura de los Poemas Matemáticos Barrocos (1967) y el sello de Vigo en la composición. La tercera es igual a la primera viñeta, la cuarta posee dos flechas en orden ascendente y en la última encontramos el "grupo de familia" emergiendo, a la manera de "nube" de pensamiento de la letra "T". Podemos decir que hay una secuenciación del contenido, signado por la repetición, la utilización de la flecha como herramientas tomadas de la estructura del comic, pero no podemos afirmar un mensaje único, legible de una manera determinada. 


\section{Hexágono 71'ac (1971)}

En Hexágono 71' ac aparece la historieta: “Características eróticas; con perforaciones". Está compuesta de un solo cuadro, donde aparece nuevamente el "grupo de familia" en el centro de la composición. De ellos se desprenden tres perforaciones ascendentes hacia la imagen de dos mujeres. A partir de un relevamiento de la biblioteca hemos encontrado que la imagen citada anteriormente fue extraída del libro presente en la Biblioteca de Vigo, Panorama des Arts Plastiques Contemporains (1960) de Jean Cassou, página 73. El libro también aparece reseńado en el artículo que Vigo escribe para El Argentino, titulado "Artes plásticas. Panorama”, como señala B. Gustavino:

La atención de Vigo a las narrativas divergentes de la propuesta por la historiografía del arte "a la francesa" se confirma en una reseña de 1961 del libro de Jean Cassou, Panorama des arts plastiques contemporaines, traducido y publicado en Espańa. El artista platense objeta que el título no aclare "en Francia", ya que el supuesto "panorama" se restringe a ese país e ignora la pintura espańola, la italiana, la holandesa, omisiones que Vigo "inaceptables en un crítico y figura de prestigio" en las artes plásticas internacionales. (Gustavino, 2015, 441)

Este ejemplo da cuenta de las múltiples formas que asume la cita en el trabajo de Vigo: apropiación, reescritura, elaboración de un texto crítico, collage, edición. Aporta indicios para reflexionar sobre el diálogo que se establece entre los materiales como insumos, acción presente de manera continua en la producción del artista, pero además, coexistencia de múltiples temporalidades y acciones sobre ese material. 
En la misma publicación aparece "Aburrimiento y Peligro" y el poema "Hombres" de Dick Higguins. La posibilidad de asociación entre el poema y la historieta de Vigo es, como señalábamos anteriormente, una de las oportunidades para el lector que ofrece la revista ensamblada. Podemos leer aquí un vínculo entre el poema en función de la viñeta antes expuesta o podemos pensar lo contrario, es decir, estas obras funcionan separadamente. Nos encontramos, nuevamente, con la apertura hacia el lector a la que enfrentan estas historietas, la dificultad, y en este sentido hermetismo, de asignar lecturas univocas a sus historietas carentes de héroes.

Hexágono 71'bc. (1972)

"Grupo de familia" aparece por tercera vez, en este caso en la historieta U.S.A. versus Latin America que en Hexágono 71' bc. Se trata de una hoja doblada longitudinalmente, donde encontramos una hendidura que traspasa las tres hojas que conforman la historieta. En la lectura de Bugnone, el texto en inglés puede vincularse con el uso de la lengua a la que se juzga: "Al abrir la hoja, se observa que el calado coincide con el caño de un arma de fuego que apunta directamente hacia el espectador, con un tratamiento pop de la imagen extendido en los Estados Unidos, lo cual también puede emparentarse con el uso del inglés en el título." (Bugnone, 29: 2014) El "grupo de familia" aquí aparece con un signo de exclamación en la parte superior, en el medio el calado -huella de la bala- y abajo la leyenda "llegó la ayuda hermanos!".

La pistola que utiliza Vigo para la composición es una reproducción de la imagen de Lichtenstein "Pistol" de 1968. La cita en este caso, se 
vincula directamente con un artista que utiliza la estética del comic para su producción y que, con variantes en la representación de la mano que sostiene el arma, ha publicado la misma obra, en la tapa de la revista Time de 1968, bajo la leyenda "THE GUN IN AMERICA”.

\section{Hexágono 71' be (1972)}

En Hexágono 71' be encontramos " $\mathrm{La}$ (in) comunicación de los medios de comunicación masivos. Por caso la TV, Comic Strip”. Es una historieta compuesta de seis cuadros, cada uno de ellos numerado y con una letra (a, b, c) en la parte inferior, a excepción de 5 y 6 . Esta doble secuenciación sugiere la continuación de la lógica de la publicación en la que está inmersa, reforzando la secuencia lineal. Compositivamente en todas se repite el esquema de división en tres espacios, en la parte superior el número 01, $02 \ldots$ en medio de la imagen (en $01,02,03,04$ ) un televisor dentro de una burbuja con diversas formas geométricas, y en la parte inferior el "grupo de familia" enmarcado en una viñeta con una de las letras del abecedario. En la imagen 5, con tipografía redondeada, (tipo sturm blond) se lee "boom", en la imagen 6, en el lugar del televisor está el "grupo de familia", sugiriendo un espejismo entre aquello que miran y ellos mismos. Además en la viñeta numero 6 ya no hay letras legibles, se yuxtaponen las anteriores formando un enjambre en la parte inferior. En "La in-comunicación”, por una parte, estos personajes se ven reflejados, pero, a su vez, son un modelo de ellos mismos, son su duplicado exacto.

Señala Vigo en la entrevista para el diario La Tribuna: "Cuando me pongo en una línea de análisis de la TV van surgiendo durante un periodo 
de tiempo TV poéticas, TV objetos, TV poemas, TV xilográficas, pero sé que dentro de mí se suman muchas facetas de las distintas especializaciones del arte (...)" (La Tribuna, Asunción, 1968). Puede establecerse un antecedente de La (In) comunicación de los medios de comunicación masivos en la publicación que antecede Hexágono $71^{\prime}$, nos referimos a Diagonal Cero. En el número 26, de 1968, Vigo publica su obra "Objeto Óptico la televisión”. Si bien el tratamiento es bien diferente, podemos establecer coincidencias respecto al refuerzo de sentido que la primera propone, esto es, si la primera, inserta en Diagonal Cero, una plataforma de poesía, refiere a una ilusión óptica, a una percepción alterada de la realidad producto del medio, puede leerse intensificada en la (In) Comunicación... Aquí los personajes se ven afectados de tal manera que se han transformado en lo que ven representado.

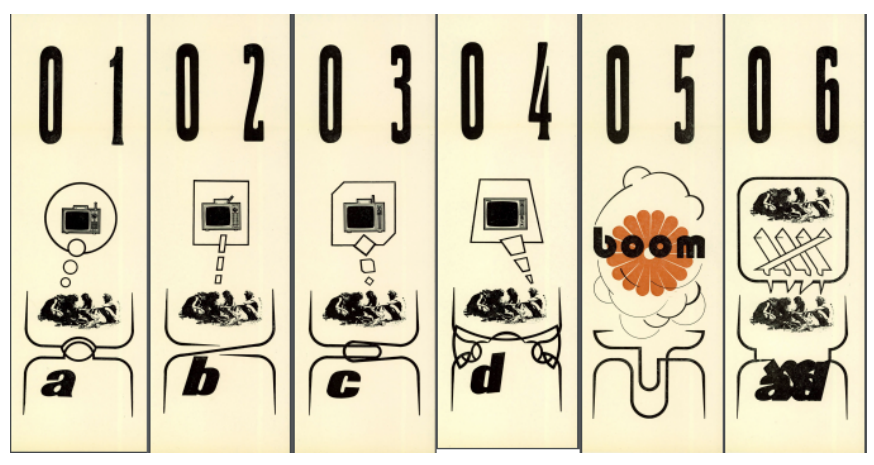

Fis. 3. E. A. Viso, La (In) comunicación de los medios de comunicación masivos. Hexágono 71'be. Fragmento. Archivo CAEV 
Historietas herméticas, aproximación a la tira dibujada desde la obra de E. A. Vigo. Julia Cisneros

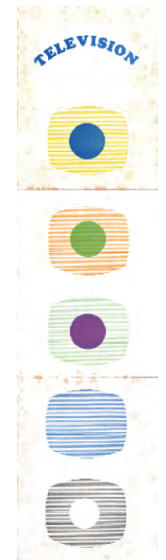

Fis. 4. E. A. Viso, Objeto Óptico la televisión Diasonal Cero n² 26, 1968. CAEV.

\section{Hexágono 71 'cd. (1973)}

En esta publicación el editor modifica la portada del sobre contenedor e intercala una imagen, sobre esta se lee "Eso si la más peligrosa".

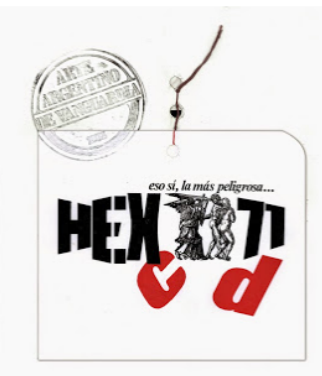

Fis. 5. Hexásono $71 \mathrm{~cd}$. Archivo CAEV 
Hay dos posibilidades de lectura respecto de este grabado de Alberto Durero fechado en 1511, titulado "La expulsión del Paraíso".

Una hipótesis radica en que Vigo tomara la imagen de algún ejemplar de Durero existente en su biblioteca; en el relevo realizado no la hemos encontrado el libro del cual lo habría obtenido. La segunda suposición se orienta a que la imagen haya sido extraída de la publicación editada por Oscar Massota, Literatura Dibujada. Serie de Documentación de la Historieta Mundial. En este caso, la imagen habría salido de un elemento absolutamente marginal de la publicación de Massota: la publicidad de la editorial Sudamericana. En la publicidad se lee: "Fabricamos una nueva forma de Paraíso, eso sí la más peligrosa”. Vigo fragmenta el contenido de la publicidad y lo vuelve a significar en un nuevo espacio. En este caso, Vigo se apropia de la publicidad para transformarla en un elemento estético de su publicación.

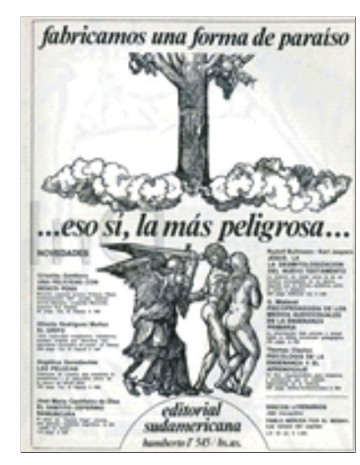

Figs. 6. Publicidad Sudamericana. L. D no 1. Página 43. Archivo CAEV. 
La misma imagen será utilizada por León Ferrari en la serie "L'osservatore Romano" (2001), que presenta como título "Conclusiones del Congreso Teológico-Pastoral organizado por el Congreso Pontificio para la Familia”.

Hexágono 71'ce (1973)

De Hexágono 71' ce destacamos por una parte el artículo firmado por Vigo titulado "Porque un arte de investigación" donde señala la importancia de reflexionar sobre el lenguaje y la función del espectador. En el arte de investigación los "lenguajes herméticos o demasiado simples han alimentado la existencia de esas dos actitudes frente al arte. Pensamos no para anular (estamos en total acuerdo en la coexistencia de ambas posturas) pero así para que exista comprensión de esa coexistencia y con un real sentido pedagógico, establecer un lenguaje accesible y a la vez cargado de problemáticas nuevas" (Vigo, 1973) resalta también la utilización de códigos conocidos sin perder la profundidad de las ideas. En este número encontramos obras de: Zabala, "Explotación es terrorismo"; "Afiche de Artistas Plásticos en Lucha" diseñado por Romero, "Fusilados en Trelew el 22 de agosto de 1972. Tribunal popular para los asesinos", Nicholas Zurbrugg, poema visual, "Large $\&$ far. Small \& near", "Envíe una idea en 200 copias a: G. Deisler"; de Vigo, "Souvenir de dolor" e "Historieta con automóvil”. 

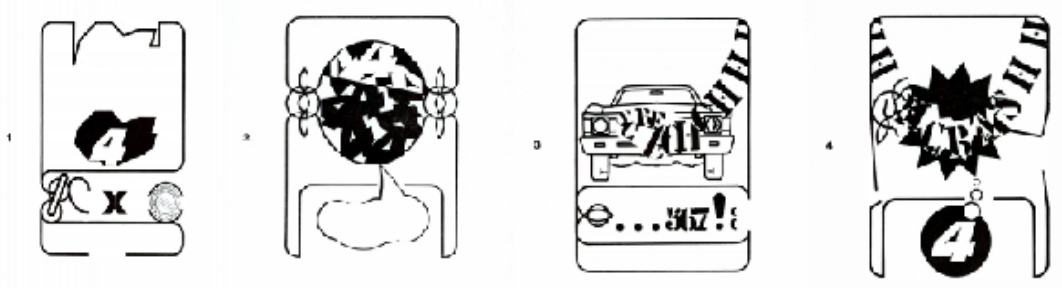

Fig. 7. Historieta con automóvil. Hexágono 71' ce Archivo CAEV.

La obra que nos ocupa, corresponde a "Historieta con automóvil". La secuencia se compone de cuatro cuadros. En el primero de ellos, una viñeta con el numero 4 con sombra en perspectiva hacia ambos lados, la parte superior de la viñeta sigue ese contorno. Una letra " $X$ " y el sello de Vigo enmarcado de forma circular aparecen en la parte inferior. En el segundo cuadro vemos una viñeta rectangular, en los costados, hacia la mitad de la composición, dos hélices de avión vistas de frente y en medio, enmarcado por un círculo, números 4 formando una composición, la mitad de ellos en blanco y la otra mitad en negro. Debajo de ellos, una burbuja invertida vacía, que también puede leerse como humo saliendo del caño de escape. En el cuadro número 3, vemos un coche Ford Falcón - ¿referencia a la huida que fue masacre de Trelew?- de frente, de donde salen letras ascendentes, parece formarse la onomatopeya "SCRECHH", debajo, una especie de viñeta con tres puntos suspensivos y los números " 567 ” con un signo de exclamación.

En el último cuadro, una estrella en forma de explosión donde se lee "CRASH", debajo de ella, el número 4 enmarcado en una burbuja 
negra - ¿sugiriendo que lo anterior es pensamiento de ese número?-, llama la atención la ruptura en la forma de esta última viñeta, ya no es una composición cerrada como las anteriores.

En marzo de 2017 se presenta El Punto Ciego, Antología de la Poesía Visual Argentina de 7000 a.C. al Tercer Milenio con textos de Perednik, Doctorovich y Estévez (2016), lo interesante es que la obra "Historieta con automóvil" aparece en una publicación destinada a la poesía visual. Como en el caso aludido respecto de Alvaro de Sá y la Novísima, la poesía visual y la historieta vuelven a emparentarse.

\section{CONCLUSIONES:}

El interés de Vigo por el género de la historieta se manifiesta, tanto en su biblioteca personal como en sus obras.

El desarrollo de este género puede verse plasmado en la revista Hexágono 71', donde de manera teórica, como editor, y práctica, como artista, desarrolla un pensamiento sobre la historieta. Una historieta que Vigo denomina hermética, puesto que, creemos, no hay posibilidad de efectuar una generalización en lo que respecta a las composiciones y los sentidos que ellas convocan. Hermético significa aquí no condicionado en su lectura, abierto a la evocación que despierte en el espectador. Las historietas de Vigo carecen de héroes, poseen recurrencias en la utilización de tipos como en el caso del "grupo de familia" pero no podemos decir que este tenga un sentido univoco en su producción. Sobre la utilización de letras y números también podemos establecer lazos con sus Poemas Matemáticos 
y las composiciones xilográficas pero tampoco corresponde una asignación univoca de sentido directo en tales manifestaciones.

Por otra parte, Vigo opera como editor no solo en sus libros de reescrituras, donde selecciona un catálogo de artículos de su interés y los transforma de manera novedosa por las formas de reorganizar esa escritura sino también en la práctica del collage, puesto que aquí la tarea de editor aparece en la elección de las imágenes en la composición de nuevos sentidos para representaciones ya existentes.

Para Vigo, un desarrollo poético sobre géneros considerados menores no implica un lenguaje llano, por el contrario: espera que el espectador participe de manera activa en la propuesta estética, decodificando los mensajes y aportando claves de lectura. Los modos de circulación que utiliza para tal fin, creemos, se corresponden con esta intencionalidad.

Para un desarrollo posterior, que excede esta presentación, sería interesante poder analizar la manera en que se incrementa el interés por las historietas en la producción de Vigo. Por ejemplo, los textos teóricos donde Vigo retoma la libre elección del lector en la interpretación de la obra, por caso Biopsia 1974 A, participación de Vigo con "Band Dessinee Hermetique Premiere" en la convocatoria del CAIC enviada al Art of sistem in latin America' 74 . Bruselas, Bélgica. 


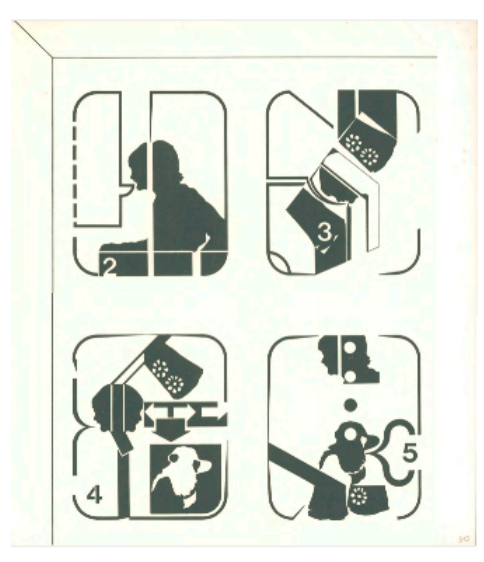

\section{Fig. 8. E. A Viso, Band Dessinee Hermetique Premiere, Biopsia 1974 A. CAEV.}

También continuar indagando en su amplia producción como comunicador a la distancia, por caso, en sus proyectos de intervención sobre una historieta hermética de su autoría.

Por último, resaltar el entrecruzamiento como operación de construcción poética sobre el que trabaja Vigo donde no solo vincula sus lecturas personales con sus publicaciones, sino también la potencialidad de los cruces entre la poesía experimental y la historieta, que se presentan en las obras a las que referimos.

\section{NOTA SOBRE LAS IMÁGENES}

Las imágenes incluidas en este trabajo fueron tomadas en el Centro de Arte Experimental Vigo, La Plata, Argentina, con autorización para ser reproducidas. 


\section{REFERENCIAS BIBLIOGRÁFICAS:}

Bugnone, Ana (Editora) La revista Hexágono 71' (1971-1975) La Plata: Edulp, 2014. Disponible en: http://bibliotecaorbistertius.fahce.unlp.edu.ar/09bugnone, consultado 15 marzo 2017.

Cirse, Moasy, Vanguardia, um projecto semiológico. Brasil: Vozes, 1975.

Castro, Maria Virginia, "Literatura Dibujada: El desafio de comprometer la historieta" Sin Fecha. Disponible en: http://americalee.cedinci.org/wpcontent/uploads/2016/07/LITERATURA-DIBUJADA_PRESENTACION. pdf consultado 2017. Consultado 21 Agosto 2017.

De Sá, Álvaro. Poemics 12x9. Brasil: Edición de Autor, 1967.

Dorfman, A. Mattelardt. Para leer al Pato Donald. Buenos Aires: Siglo XXI, 2005.

ECO, Umberto. Apocalípticos e Integrados. España: Lumen, 1968.

Gustavino, B. (2012). Relevamiento de Libros artesanales de Vigo. CAEV. (2015). Relatos sobre el arte moderno en las bibliotecas argentinas. Pistas halladas en el archivo y la biblioteca Antonio Vigo en História Da Arte: Coleções, Arquivos E Narrativas Urutau ltda. Brasil.

Serie Archivo Novisima Poesía 69, CAEV.

Massota, Oscar. La historieta en el mundo moderno. España: Paidos, 1970.

Rivera, Jorge. Panorama de la Historieta en la Argentina. Buenos Aires: Libros del Quirquincho, 1992

Vigo, Edgardo Antonio. Hexágono 71', colección completa CAEV. Disponible: http://www.caev.com.ar/

Exposición: Fragmentos de la Microedición, Centro Cultural Ricardo Rojas, curada por Alejandro Bidegaray y Alejandro Schmied. Agosto de 2017. Buenos Aires, Argentina. Sin Catálogo. 